\title{
Population dynamics of southern elephant seals: a synthesis of three decades of demographic research at Marion Island
}

\author{
PA Pistorius $^{1 *}$, PJN de Bruyn ${ }^{2}$ and MN Bester ${ }^{2}$ \\ ${ }^{1}$ Department of Zoology, Nelson Mandela Metropolitan University, South Campus, Port Elizabeth 6031, \\ South Africa \\ ${ }^{2}$ Mammal Research Institute, Department of Zoology and Entomology, University of Pretoria, Private \\ Bag X20, Hatfield, 0028, South Africa \\ ${ }^{*}$ Corresponding author, e-mail: Pierre.pistorius@nmmu.ac.za
}

\begin{abstract}
Southern elephant seal numbers declined precipitously throughout most of their circumpolar distribution, including Marion Island, following the 1950's. A long-term intensive demographic programme was initiated in 1983 on the relatively small population at Marion Island in an attempt to identify causative mechanisms associated with this decline. Weaned southern elephant seal pups have been tagged annually since 1983, and this has produced a large number of individuals of known identity. A regular resighting programme yielded a mark-recapture dataset that has been subjected to numerous survival-based models. This ongoing programme produced a substantial body of scientific literature on population growth patterns, vital rates (survival and fecundity) and population regulation in southern elephant seals which we review in this manuscript. We briefly describe the analytical framework common to much of the demographic research and highlight important conclusions regarding elephant seal population regulation at Marion Island. We also discuss priorities for future research.
\end{abstract}


Key words: environmental change, fecundity, growth, mark-recapture, population regulation, southern elephant seals, survival

\section{Introduction}

The study of life history characteristics that govern population growth is firmly entrenched in the discipline of population ecology and is of applied value but also of theoretical interest (Gaillard et al. 1998, Saether et al. 2002, Baker and Thompson 2007). Understanding the means of population regulation as well as being able to discern which vital rates and population components are the most responsive to environmental change has obvious merit in applied fields such as wildlife management (Schwarz and Stobo 2000, Sibly et al. 2005, Lande et al. 2006, Hone and Clutton-Brock 2007). Population growth is furthermore disproportionally influenced by certain population parameters (Gaillard et al. 1998, Pistorius 2001, McMahon et al. 2005b). Being able to identify which vital rates (fecundity or survival) and what age categories are the most important in causing population change is important in the management of populations, particularly when dealing with species that are of conservation concern or that impact on human welfare (Jorgenson et al. 1997, Holmes et al. 2007). Although often subject to stringent assumptions, longitudinal studies of survival and fecundity have long been recognized as potentially yielding robust estimates, free of a number of biases associated with cross-sectional or short term studies (Caughley 1977). Possibly the most important source of bias in cross-sectional population models is related to the assumption that the age distribution in the population under study is stationary, an unlikely scenario for most wild populations (Caughley 1977). Longitudinal studies are, however, labour intensive and lengthy in duration necessitating a long-term commitment to the study (Lebreton et al. 1992). 
One such study, which has arguably resulted in one of the most comprehensively investigated large mammal populations from a demographic point of view, commenced in 1983 on southern elephant seals at Marion Island (Bester and Wilkinson 1994, Pistorius et al. 1999a). High levels of philopatry to natal sites during obligatory terrestrial phases (Condy 1979, Hofmeyr 2000), and relative immobility and associated ease of identifying uniquely marked individuals (Pistorius et al. 2000, de Bruyn et al. 2008), have rendered this a prime candidate species for studies of population ecology (e.g. Pistorius et al. 1999a, McMahon et al. 2003), life history theory (Pistorius et al. 2004, 2008a) and large scale environmental change (McMahon and Burton 2005).

The Marion Island population of this circumpolar species (Ling and Bryden 1992) is relatively small, and like most other populations in the southern Indian and Pacific oceans (Burton 1986, Hindell and Burton 1987, Guinet et al. 1992, McMahon et al. 2005a, Authier et al. 2010), declined precipitously during the four decades following the mid 1950s (Pistorius et al. 2004, McMahon et al. 2009). The concern raised by this general decline stimulated the initiation of several long-term ecological studies on southern elephant seal populations around the subantarctic (Bester 1988, Hindell 1991, Bester and Wilkinson 1994). The focus was largely on changes in population sizes (Hindell and Burton 1987, Guinet et al. 1992, 1999, Bester and Wilkinson 1994, Pistorius et al. 1999b), and causal factors contributing to these changes, both proximate and ultimate (Hindell 1991, Bester and Wilkinson 1994, Pistorius et al. 1999a). The Marion Island population declined by $83 \%$ between 1951 and 1994 and by $37.2 \%$ from some 2120 individuals in 1986 to 1330 individuals in 1994 at an average of 5.8\% per annum, and 3.7\% up to 1997 (Pistorius et al. 1999b, McMahon et al. 2009). Although no significant reduction in population numbers was evident post 1994 (Pistorius et al. 2004; see Figure 1 for pup counts as a proxy for population size), an inflexion in 
population growth (marking the change between a decline and increase in growth) only took place in 1997 (McMahon et al. 2009). The population appeared stable between 1994 and 1999 (Pistorius et al. 2004), although a recent analysis with additional years of population counts indicated that these years were associated with an inflexion in population growth (McMahon et al. 2009). De Bruyn (2009) recently identified the inflexion in population survivorship as being 1994, and postulated this to have resulted in a population trend inflexion around 1998. Either way, the relatively stable population between 1994 and 1999 allowed for the study of age- and state specific vital rates during two distinct population trajectories (e.g. Pistorius et al. 2008b). Therefore inferences regarding causative factors associated with change in numbers in this population became possible.

The intensive mark-recapture database, developed since 1983, has been subjected to numerous analyses resulting in a host of scientific papers that deal with specific aspects of survival and fecundity, particularly in relation to population regulation and life history theory. The aim of this review is to provide a synthesis of this work, bringing forward our current understanding of population parameters and their role in population regulation in southern elephant seals at Marion Island. We highlight future research priorities, specifically at this site, but that may also be relevant elsewhere.

\section{The mark-recapture framework}

\section{Study site}

Subantarctic Marion Island $\left(46^{\circ} 54^{\prime} \mathrm{S}, 37^{\circ} 45^{\prime} \mathrm{E}\right.$; Figure 1) is located in the southern Indian Ocean, approximately $2180 \mathrm{~km}$ south-east of Cape Town, South Africa. It is 300 $\mathrm{km}^{2}$ in area with a coastline of approximately $90 \mathrm{~km}$ of varied physiognomy (Wilkinson 
et al. 1987) predominated by cliff faces. Southern elephant seals regularly haul out on 54 beaches along a $51.9 \mathrm{~km}$ coastline mainly on the eastern side of the island between Storm Petrel and Goodhope bays (Figure 1). Neighbouring Prince Edward Island ( 22 $\mathrm{km}$ northeast) is the only other island in the archipelago and is much smaller in size (46 $\mathrm{km}^{2}$ ). The closest land mass to the Prince Edward Islands group is Île aux Cochons of the Crozet archipelago, a French possession, about $950 \mathrm{~km}$ to the east. Chown and Froneman (2008) provides further ecological details of Marion Island.

\section{Data collection and analyses}

Since 1983, a total of 13,400 recently weaned southern elephant seal pups were tagged in both of their hind flippers on an annual basis (average: 479; range: 389 - 700). Figure 2 shows the number of pups born at Marion Island, the number tagged at weaning and the number of pups surviving to weaning age that were not tagged. Virtually all pups that survived to weaning age were tagged, particularly in the most recent 15 years. Uniquely numbered, colour-coded Dal 008 Jumbotags ${ }^{\circledR}$ (Dalton Supplies Ltd., Henleyon-Thames, United Kingdom) were used for this purpose. Initially, pups were tagged in either of the two inner inter-digital webbings of each hind flipper (see Pistorius et al. 2000 for details). However, the tag site was changed from the year 2000 onwards, to the upper, outer inter-digital webbing of each hind flipper (Oosthuizen et al. 2010) to facilitate the sighting of tags. Date, location and the sex of the pup was recorded at tagging. In addition, since 2006, Supersmall® tags (Dalton Supplies Ltd., Henley-onThames, United Kingdom) were deployed in the inner inter-digital webbing of the right hind flipper in unweaned pups prior to the usual tagging regime at weaning age (de Bruyn et al. 2008). In consequence, between 2006 and 2010, this protocol allowed for 
identification of mother-pup relatedness of an average of 148 pups (range $109-176$ ) annually (de Bruyn et al. 2008).

Since 1983, all the beaches where southern elephant seals regularly haul out, were checked weekly during the breeding season (mid-August to mid-November), and every ten days outside the breeding season, for tagged southern elephant seals. For each tagged seal encountered, efforts were made to read the tag number and record the colour combination, as well as number of tags remaining.

The large majority of demographic studies covered in this paper made use of broadly similar analytical procedures which are briefly described below. Encounterhistory matrices, which are required for mark-recapture analyses, were constructed from resight data. Multiple sightings during any given year were treated as a single sighting. The peak haul-out date for females during the breeding season is 15 October (Condy 1978, Bester and Wilkinson 1994), and animals were assumed to age on this date. The software program MARK (G. White, Colorado State University; White and Burnham 1999), which is an application for the analysis of encounter-history matrices of marked individuals, was used to obtain likelihood estimates of annual survival and resighting (capture) probabilities. The software program provides parameter estimates under the essential Cormack-Jolly-Seber (CJS) model, but also under a range of models that appear as special cases of this model (Lebreton et al. 1992).

The two fundamental parameters in these models are: the survival probability for all animals between the $i$ th and $(i+1)$ th encounter occasion, and the resighting probability for all animals in the $i$ th encounter occasion.

The survival probability incorporates both death and permanent emigration of individuals and can therefore be referred to as apparent survival. In all relevant papers it was assumed that southern elephant seals show a strong site fidelity to their natal 
grounds (Hofmeyr 2000) and that permanent emigration from Marion Island is minimal. Although these assumptions are generally applicable, recent work provides evidence that the assumption must be applied with caution for future work (de Bruyn 2009, Oosthuizen et al. 2009, Oosthuizen 2010) (see below).

Model fit to the data were mostly assessed using the program RELEASE goodness-of-fit procedure (Burnham et al. 1987) implemented in program MARK to ascertain whether the assumptions pertaining to the model were met (see Lebreton et al. 1992). An information theoretic approach was used for model selection (Burnham and Anderson 2002) during which a set of models, including fully parameterized models and models with various constraints on survival and resight probability were compared. We used the small sample corrected Akaike's Information Criterion (AICc) to select the best models. AIC is a standard procedure for model selection in a mark-recapture context, and it weighs the quality of fit or deviance (defined as the difference in -2Log (Likelihood) of the current model and $-2 \log ($ Likelihood) of the saturated model) and the precision (via the number of estimable parameters), so as to select the most parsimonious model that adequately describes the data (Lebreton et al. 1993, Anderson et al. 1994).

The survival models used rely on the resight probability at each resight occasion in order to allow for survival estimation. This parameter in itself is also of interest and was used in the estimation of reproductive rates and costs associated with reproduction in southern elephant seals at Marion Island (e.g. Pistorius et al. 2001a, but see Bradshaw et al. 2002).

Notwithstanding the change in tag-site in 2000, elephant seals at Marion Island have been tagged in both hind flippers since the commencement of the mark-recapture programme in 1983 (Bester \& Wilkinson 1994, Pistorius et al. 2000, de Bruyn et al. 
2008, Oosthuizen et al. 2010). This allowed for the assessment of the potential for bias in estimates of survival rates resulting from tag-loss and the subsequent estimation of correction factors to compensate for such tag loss (Wilkinson and Bester 1997, Pistorius et al. 2000, Oosthuizen et al. 2010). Correction factors have consistently been applied to survival estimates (Wilkinson and Bester 1997, Pistorius et al. 2000, Oosthuizen et al. 2010). McMahon and White (2009) demonstrated in their study at Macquarie Island that the independence in tag loss rates (between flippers on the same individual) as assumed at Marion Island (Pistorius et al. 2000) is incorrect. Potential biases in demographic parameters related to violation of this assumption at this study location is likely to be minimal due to the low rates of tag loss that have been reported here (Pistorius et al. 2000, Oosthuizen et al. 2010).

\section{Discussion}

Important in the assessment of mechanisms associated with population regulation is the availability of robust estimates of vital rates that potentially influence population growth, these being survival, or its inverse, mortality, and fecundity (Pistorius et al. 2001b, McMahon et al. 2005, Harting et al. 2007, Holmes et al. 2007, Bradshaw and McMahon 2008; Figure 3). In gauging the influence of the environment on population growth, it is furthermore important to be able to assess temporal variability in these vital rates (Beauplet et al. 2005, Baker et al. 2007). These are ideally studied at an age- or state-specific level so that population components proximately related to observed population change can be identified (Wisdom et al. 2000, Coulson et al. 2005).

Although successful reproduction is an obvious condition for population maintenance, in long lived animals such as southern elephant seals, its role is generally thought to be inferior to that of survival in governing population growth (Lima and Paez 
1997, Saether 1997, Gaillard et al. 1998, Pistorius 2001, McMahon et al. 2005b; Figure 3). Notwithstanding, its demographic function, together with the information that can be gleaned regarding intrinsic and extrinsic drivers of population change (Gaillard et al. 1992, Jorgenson et al. 1993, Saether 1997, Bowen et al. 2006, Harting et al. 2007, de Little et al. 2007), warrants the study of reproductive rates in animal populations. For example, a decrease in age of maturity and increase in age-specific fecundity were observed in the declining Marion Island southern elephant seal population, suggesting a density dependent response (Pistorius et al. 2001b; but see Bradshaw et al. 2002). Body size is generally thought to be the fundamental criterion affecting age of primiparity (Laws 1956, Reimers 1983, Boyd 2000). It is likely that per capita prey availability, this being made up of various fish and squid species (Rodhouse et al. 1992, Daneri and Carlini 2002, Daneri et al. 2000, van den Hoff et al. 2003, Hindell et al. 2003, van den Hoff et al. 2003), increased as the southern elephant seal population declined (Pistorius et al. 2001b). This would consequently have allowed for accelerated growth and improved body condition which would have stimulated the above shifts in reproductive rates, a pattern also observed elsewhere (Huber et al. 1991, Gaillard et al. 1992, Saether 1997). However, at Marion Island, accelerated growth and improved body condition of individuals could not be directly measured, and the assessment of these measures and others associated with individual experience and status represents an important covariate alongside vital rates for assessment in future studies (de Bruyn et al. 2009). Age of primiparity varies between three and six for this population, with fecundity on average being 0.16 (SE 0.04), 0.40 (SE 0.07), 0.45 (SE 0.07) and 0.50 (SE 0.060) respectively (Pistorius et al. 2001b). Through life table analyses, and stochastic growth models, it has become clear that fecundity plays a relatively minor role in population growth in this population, which required unrealistic adjustments to this variable in 
order to significantly change the population trajectory (Bester and Wilkinson 1994, Pistorius 2001, McMahon et al. 2005). In a food limited environment, reproduction may, however, be expected to be the first demographic variable to be compromised (Fowler et al. 1987). This indeed appears to be the case for southern elephant seals, rendering fecundity a useful variable to monitor in order to assess changes in the environment.

Recent work has, however, questioned the validity of using age-specific resight probabilities during the breeding season as a rational index of age-specific breeding probabilities (de Bruyn et al. in press). On the other hand, detectability of seals actually present at the island approaches $100 \%$, justifying under certain circumstances, the use of such an index (de Bruyn et al. in press). However, this approach assumes that after primiparity, females of the species breed virtually every year, which has recently been shown to not be the case at Marion Island (de Bruyn et al. in press). Several studies addressed questions associated with demographics of adult female southern elephant seals basing conclusions on this tenuous assumption (e.g. Hindell 1991, Pistorius and Bester 2002, McMahon et al. 2003, 2005b, Pistorius et al. 2004, 2008b). Reproductive estimates derived from such studies must therefore be viewed with some caution although the potential bias in point estimates of fecundity is likely to be similar over time and different adult female age groups, thereby validating temporal and groupspecific comparisons to some degree.

In colonial breeding animals, particularly those in which breeding activities are compressed within a relatively narrow window of opportunity, mortality of immatures during the course of the breeding season has the potential to largely impact on a population's trajectory (Boveng et al. 2000). This is particularly true in seabirds and seals in which relatively short periods of food shortage could hamper provisioning rates 
or adult body condition and translate into high juvenile mortality levels (Soto et al. 2004). Weather conditions (most notably storms and heavy rainfall), breeding activities associated with male dominance and topography and substrate of breeding habitat, could also influence levels of early juvenile mortality in seals (Chilvers et al. 2005, Frederikson et al. 2008). In southern elephant seals breeding at Marion Island, pup mortality, however, does not appear to play a large role in governing population growth. Pup mortality during the course of the breeding season is about $4 \%$ at Marion Island with no relationship to population density (Wilkinson 1992, Pistorius et al. 2001a), similar (McCann 1985, Hindell and Burton 1987) and slightly higher (Galimberti and Boitani 1999) to what had been reported at other breeding sites. As opposed to some populations of Northern elephant seals, in which pup survival is largely impacted through storms (Stewart 1992), weather conditions do not appear to play a large role in pup survival at Marion Island. Furthermore, smaller harems at Marion Island tend to have the highest level of pup mortality, probably due to the presence of younger, less experienced females but also possibly due to suboptimal harem sites (Pistorius et al. 2001a).

Juvenile survival (post weaning survival over the first three years of life prior to sexual maturity; Pistorius et al. 2001b, McMahon et al. 2005a) is often a key component of population dynamics, largely influencing population status in many large-mammal populations (Eberhardt and Siniff 1977, Eberhardt 1981, Promislow and Harvey 1990, Hindell et al. 1994, York 1994, Benton et al. 1995, Jorgenson et al. 1997, Hastings et al. 1999). It has furthermore been purported to be particularly sensitive to environmental variability (Fryxell 1987, Gaillard et al. 1998), while at Marion Island greater variability has been evident in adult rather than juvenile survival (Pistorius et al. 1999a, Pistorius and Bester 2002). Although the decline in several pinniped populations was attributed to 
low juvenile survival (Trites and Larkin 1989, Hindell 1991, York 1994), it is uncertain whether low juvenile survival was proximately related to the decline of southern elephant seals at Marion Island (Pistorius and Bester 2002, McMahon et al. 2003). However, it did not show significant change concurrent with the change in population growth, which is opposite to what was found for adult female survival (Pistorius et al. 2004, 2008a). Based on population matrix models (Caswell 2001) applied to the Marion Island population, Pistorius (2001) found population growth to be more sensitive to proportional changes in adult female as opposed to juvenile survival (Figure 3). McMahon et al. (2005a), however, found a marginally higher elasticity in juvenile survival for the same population. As noted by de Bruyn (2009), the different result was probably due to different delineations between juveniles and adults (females in their fourth year, a proportion of which pup every year (Bester and Wilkinson 1994, Pistorius et al. 2001b) was assigned to the juvenile class by McMahon et al. (2005a) and the adult class by Pistorius (2001)). A comparative increase in survival of females in their fourth year (Pistorius et al. 2004) appears to have preceded an increase in survival of older females (de Bruyn 2009). Irrespective of whether growth in this population is more sensitive to equivalent changes in juvenile or adult survival, the fact that juvenile survival (at least during the first three years of life) was stationary (Pistorius et al. 2002) during a period of significant change in population growth (which was initially questioned (Bradshaw et al. 2002), but has since been confirmed (Pistorius et al. 2004, McMahon et al. 2009)) argues against it having been the primary driver associated with population change at Marion Island (Figure 3). During the first three years of life, survival in this population was 0.60 (SE 0.01), 0.81 (SE 0.02) and 0.78 (SE 0.02) and not significantly influenced by gender (Pistorius and Bester 2002a; see also McMahon et al. (1999), Pistorius et al. (1999a) and de Bruyn (2009)). First year survival does, 
however, relate to weaning mass in a particular year (McMahon et al. 1999, McMahon et al. 2000, 2003; McMahon and Bradshaw 2004; McMahon and Burton 2005; de Little et al. 2007).

A proportion of juvenile southern elephant seals haul out during winter. This is often termed a winter or resting haul-out with no particular function ascribed to it (Kirkman et al. 2001). An investigation into the fitness implications associated with this behaviour revealed that participation in this haul-out bears no survival implications (Pistorius et al. 2002). It is, however, likely to be related to differential levels of philopatry among individuals (Pistorius et al. 2002).

Southern elephant seals are at the extreme ends with regards to both sexual dimorphism and polygamy in marine mammals (Laws 1956) resulting in marked structural and functional differences between the sexes and a pronounced disparity in sex-specific adult survival (Promislow 1992, Pistorius et al. 1999a, de Bruyn 2009). Greater susceptibility to nutritional stress and aggressive behaviour associated with male dominance results in relatively low survival in adult males (Toigo et al. 1997), about 0.69 (averaged over $6^{\text {th }}$ to $11^{\text {th }}$ year; Pistorius et al. 1999a), yet males are not a limiting resource when it comes to ensuring fertilization of females during the breeding season (Wilkinson and van Aarde 1999). Adult female survival, particularly that of primiparous females (Figure 3), however, appears to be important in governing growth in this population (Pistorius et al. 2004, de Bruyn 2009). A comparison of adult female survival at Marion Island during two population trajectories (declining and stable) and that for females at the increasing population at Peninsula Valdés Argentina demonstrated a positive relationship between adult female survival, 0.77 (SE 0.01), 0.83 (SE 0.01) and 0.84 (SE 0.03) for the three population trajectories respectively, and population growth (Pistorius et al. 2004). This is further supported by adult female 
survival being substantially higher at $88 \%$ at the large stable population at South Georgia, but with similar juvenile survival as at Marion Island (McCann 1985, Pistorius et al. 2002). The increase of $6.2 \%$ in adult female survival at Marion Island associated with the change in population growth is thought to have facilitated the levelling off in population numbers after the long term decline (Pistorius et al. 2004). Moreover, adult females, especially prior to and soon after primiparity while still growing somatically (Laws 1956), are likely to be susceptible to nutritional stress (Oftedal et al. 1987, Carlini et al. 1997, Hastings et al. 1999), and their survival seems to have been largely related to the decline in southern elephant seal numbers at Marion Island (Pistorius et al. 2004, Pistorius et al. 2008a; Figure 3). High energetic requirements resulting from foetus nourishment and accumulation of sufficient fat reserves required for lactation may explain the pronounced changes in adult rather than juvenile survival associated with a presumed increase in food availability (Pistorius and Bester 2002, Pistorius et al. 2004). A similar pattern to that described above for adult females has also been reported for pubescent southern elephant seal males. These males have unusually high energetic demands, and their survival is also related to population growth (Pistorius et al. 2005). The above therefore provides further support in favour of the food limitation hypothesis (Pistorius et al. 1999b, McMahon et al. 2005a).

The annual cycle of southern elephant seal females can be divided into two pelagic phases partitioned by distinct and highly synchronized terrestrial phases namely breeding and moulting (Condy 1979, Kirkman et al. 2003). Except for mortality incurred soon after birth during the breeding season (Pistorius et al. 2001a, McMahon and Bradshaw 2004), mortality on land in southern elephant seals at Marion Island is negligible. Using resight data independently collected during the moulting and breeding season allowed for an investigation into the seasonal components of adult female 
survival during the two intervening pelagic phases (Pistorius et al. 2008a). Postbreeding survival (62 days) of primiparous females was on average estimated at 0.83 (SE 0.02) compared to 0.92 (SE 0.02) for more experienced females. This indicates a cost associated with first reproduction, which is dependent on population status, which in turn appears to be governed by food availability (Tavecchia et al. 2005, Hadley et al. 2007, Pistorius et al. 2008a, de Bruyn 2009). Post-moulting survival (255 days) was 0.85 (SE 0.01) and independent of reproductive history. In per unit time this implies much lower survival during the post-breeding pelagic phase. This is perhaps not surprising since a complete separation from food resources takes place during the 3 and 4 weeks while on land during breeding and moulting respectively (Condy 1979, Kirkman et al. 2003). This, in conjunction with the costs associated with weaning of a pup during the breeding season, is likely to render post-breeding females at a high risk of starvation relative to post-moulting females. Post-breeding survival of primiparous females, furthermore, increased by eight percent concurrent with the termination of the population decline whereas post-moulting survival increased by 5.5 percent (Pistorius et al. 2008a). Individual variation in seal body size, regardless of age, will affect foraging ability (Weise et al. 2010) and consequently the ability to survive periods of food limitation, and the demands of pup provisioning (Wheatley et al. 2006). Assessment of known-age female body size fluctuation over time, as related to her survival, and that of her offspring has been suggested as a research priority at Marion Island (de Bruyn et al. 2008). Recent advances in the use of photogrammetry that facilitate relatively simple, but accurate mass estimation of adult elephant seals will allow this covariate to be incorporated into future survivorship modelling (de Bruyn et al. 2009). Adult female survival during the two pelagic phases furthermore varies independently (Pistorius et al. 2008a) highlighting the importance of studying survival (and covariates such as body 
mass as associated with foraging ecology - McIntyre et al. 2010, Tosh 2010) in this species at a seasonal scale, especially when ascertaining the effect of environmental variability on survival.

Food limitation is thought to have been ultimately related to the decline in southern elephant seals at Marion Island, and it is likely that food conditions improved in recent years giving rise to the observed changes in population growth (Pistorius et al. 1999b, Pistorius et al. 2008b, McMahon et al. 2009). Reasons for changes in food availability, however, remain speculative (see Tosh 2010), although in situ observations of ocean structure has enhanced our understanding of the marine environment that southern elephant seals utilise (Charrassin et al. 2008). Although it is likely that changes in food availability have been associated with large scale environmental change as previously argued (Hindell 1991, Pistorius et al. 1999a, Reid and Croxall 2001, McMahon et al. 2003, Weimerskirch et al. 2003, de Bruyn 2009), evidence for an association between proxies for environmental change, such as Sea Surface Temperature and El Niño Southern Oscillation (ENSO), expressed as the Southern Oscillation Index (SOI), remains scant for this species (McMahon and Burton 2005, de Little et al. 2007; also see Nevoux et al. 2007, 2010 for other species examples). During the analyses of seasonal resight data of southern elephant seals (Pistorius et al. 2008a), inclusion of both of these proxies as predictive variables associated with survival did not improve model fit ( $\triangle \mathrm{AIC}>2$; Pistorius unpublished data), a similar pattern observed by McMahon et al. (2009) in terms of population numbers and population growth. However, large scale environmental variability, as measured by the SOI, does appear to influence pup survival in southern elephant seals elsewhere (McMahon and Burton 2005). As a result of extensive foraging distributions in southern elephant seals (Bester 1989, Jonker and Bester 1997, Campagna et al. 1999, Hindell et al. 2003, Bradshaw et 
al. 2004, Biuw et al. 2007, Tosh et al. 2009, Tosh 2010), their life history parameters reflect the productivity of large ocean ecosystems, and render them important potential indicator species of large scale environmental change (McMahon et al. 2003). Nonetheless, despite changes in their numbers being attributed to large scale environmental processes (Hindell 1991, Pistorius et al. 1999a, McMahon et al. 2008), the mechanism/s involved remain poorly understood. It may be associated with a large scale ecosystem 'regime shift' in the southern ocean (Weimerskirch et al. 2003), and such a shift could potentially be linked to the extent of sea-ice in the Southern Ocean which impacts strongly on ocean productivity (Atkinson et al. 2004, McMahon and Burton 2005). Should large scale environmental change be instrumental in regulation of southern elephant seal populations, it is important to be able to quantify the relationship between large scale physical processes (e.g. Antarctic Circumpolar Wave and SOI) and southern elephant seal demographic rates (de Little et at. 2007), mediated through their food resources. It is consequently imperative that efforts be made to better understand these mechanisms involved so as to allow information on life history variability to be useful in an assessment of the state of the Southern Ocean ecosystem. Such studies, particularly when relating survival to large scale processes, are likely to be best rewarded at a seasonal rather than annual scale of investigation (Pistorius et al. 2008a).

As the only predator of southern elephant seals at Marion Island, killer whales could be impacting on growth in this population (Pistorius et al. 2002c, McMahon et al. 2003, Reisinger et al. in press). A recent analysis, however, indicates this predation pressure to be insufficient to dramatically impact on the southern elephant seal population trend (Reisinger et al. in press, Figure 3). Numerous observations have confirmed that killer whales predate on southern elephant seals at Marion Island (Reisinger et al. in press), but the fact that changes in survival observed were not 
uniform across demographic groups argues against predation having had a large impact on the status of this population. Furthermore, killer whales appear to preferentially target post-weaning juvenile seals (based on the peak in their numbers around the island during the breeding compared to any of the moulting seasons), and first year survival has been relatively high and constant (Pistorius and Bester 2002a, Pistorius et al. 2002).

Research on ageing is fundamental to the understanding of life-history parameters and their consequences on population demography. Senescence, generally viewed as the rate of increase in age-specific mortality or reduction in reproductive rates with age, which results from degenerative changes in the organism (Abrams 1991, Promislow 1991, Nussey et al. 2008), is widely encountered in wild populations (Caughley 1966, Eberhardt 1985, Promislow 1991, Gaillard et al. 1993, 1994, Jorgenson et al. 1997). Nevertheless, during one of the first long term studies of senescence in a marine mammal, making use of mark-recapture data, a senescence effect (reduction in either survival or fecundity) could not be demonstrated for southern elephant seals at Marion Island (Pistorius and Bester 2002). However, subsequent analysis, including an additional decade of mark-recapture data, provided evidence for reproductive senescence in female elephant seals after the age of 12 , and this effect was skewed towards individuals exhibiting early primiparity (de Bruyn 2009). Despite a dataset encompassing 25 years of longitudinal data, that extends beyond the observed longevity of the species (Hindell and Little 1988), no evidence for actuarial senescence was found (de Bruyn 2009). It has therefore been argued that mortality over the different age classes in southern elephant seals at Marion Island results in no individuals surviving to the age where physiological decline becomes a mortality agent or result in failure to breed (Pistorius and Bester 2002, de Bruyn 2009). This may be a result of the toll that food limitation takes on survival, as several previous studies that had detected 
senescence dealt with populations where adults, unconstrained by food availability, had high annual survival (Gaillard et al. 1993, Jorgenson et al. 1997). Conversely, the analytical procedures employed by Pistorius and Bester (2002) and de Bruyn (2009) may not be optimal for describing the presence/absence of senescence (de Bruyn unpubl. data). Senescence may be better described using continuous models (e.g. Loison et al. 1999). Mark-recapture procedures for fitting Gompertz and Weibull models explicitly may also provide a more reliable test of senescence (e.g. Gaillard et al. 2004).

Density dependence is a widely recognized form of population regulation (Brook and Bradshaw 2006). In essence it entails a density feedback on population parameters as a result of per capita resources being dependent on population density. Density dependence has most commonly been demonstrated in terms of food availability (e.g. Festa-Bianchet et al. 2003). As population numbers change, so does the rate of food consumption, ultimately leaving more or less food per individual. This in turn impacts on either or both survival and reproduction altering population growth and ultimately population numbers. In southern elephant seals at Marion Island density dependent population regulation was initially inferred when increased rates of reproduction and earlier onset of maturity were observed for females (see above). Although this inference was criticised because of premature speculation regarding a change in population growth rate (Bradshaw et al. 2002, Pistorius et al. 2001b), these changes were confirmed at a later stage (Pistorius et al. 2004, Pistorius et al. 2008b, McMahon et al. 2009).

Underpinning much of the demographic work that was performed on southern elephant seals is the assumption that the respective populations are negligibly influenced by permanent immigration and emigration. In the estimation of survival rates, emigration is particularly important in survival models as it functionally translates 
into mortality resulting in negatively biased estimates (Lebreton et al. 1992). The assumption of low levels of dispersal (especially emigration) in the southern elephant seal population at Marion Island is founded in the high philopatry between natal- and later haul-out sites of the species at this locality (Hofmeyr 2000), and the appreciable genetic differences between the major global stocks of southern elephant seals indicating minimal cross-dispersal (Slade et al. 1998, McMahon et al. 2005a). However, firstly, dispersal across stocks is not required for an animal to be lost to a markrecapture study if more than one haul-out locality (island) is available within the geographic limits of one 'stock' (de Bruyn 2009). Secondly, Hofmeyr (2000) based his philopatric analyses on tagged animals from Marion Island returning to sites on the island, and suggested high fidelity to natal sites. However, these analyses could not identify temporary emigration of tagged seals, even if their fidelity to their natal site was high at each visit to this island (de Bruyn 2009). Field observations of large numbers of unmarked seals present at Marion Island (Oosthuizen et al. in press) further challenged our confidence in assumptions of a closed-population, given that tag loss could not account for these unmarked seals (Oosthuizen et al. 2010). The question arose, if so many immigrants haul out at Marion Island, how many native tagged seals could be similarly hauling out elsewhere? Even low levels of migration in a small population can potentially significantly influence population growth (McMahon et al. 2005b). Also, do the tagged and untagged components of the local population adhere to similar regulatory parameters, being of different origin and subject to differing local behaviour and haulout patterns (Oosthuizen et al. in press-a)? Some temporary migration between Marion and nearby ( $22 \mathrm{~km}$ distant) Prince Edward Island is now known to take place (Oosthuizen et al. 2009), with several studies having reported on more widespread movement of marked elephant seals within the region (Bester 1988, 
Guinet et al. 1992, Reisinger and Bester 2010, Oosthuizen et al. in press-b). These recent findings suggest that emigration from Marion Island does take place and in all likelihood at least partially impacted on demographic variables that were derived from tagged individuals. It is, however, reasonable to assume similar rates of emigration throughout the study. Age-specific temporal comparisons would therefore not have been adversely affected, although point estimates of survival may have been negatively biased. In terms of population numbers, however, immigration from the larger Indian Ocean colonies is likely to balance, or even exceed immigration. It is recommended that a multistate modelling approach, including an 'unobservable' state to explain the suggested Markovian temporary emigration of seals from the study site (Kendall and Nichols 2002, Schaub et al. 2004), be implemented in future mark-recapture based life history studies on this population.

\section{Acknowledgements}

The Department of Environmental Affairs provided both financial and logistical support for research at Marion Island in earlier years. More recently the Department of Science and Technology provided the funding, managed by the National Research Foundation. Thanks to Clive McMahon and an anonymous reviewer for comments on an earlier version of the manuscript. We are indebted to numerous field personnel for their dedicated marking and resighting of elephant seals on Marion Island when we were not in the field. 


\section{References}

Abrams P. 1991. Fitness costs of senescence: the evolutionary importance of events in early adult life. Evolutionary Ecology 5: 343-360.

Anderson DR, Burnham KP, White GC. 1994. AIC model selection in overdispersed capture-recapture data. Ecology 75: 1780-1793.

Atkinson A, Siegel V, Pakhomov E, Rothery P. 2004. Long-term decline in krill stock and increase in salps within the Southern Ocean. Nature 432: 100-103.

Authier M, Delord K, Guinet C. 2010. Population trends of female elephant seals breeding on the Courbet Peninsula, îles Kerguelen. Polar Biology: 1-10.

Baker JD, Thompson PM. 2007. Temporal and spatial variation in age-specific survival rates of a long-lived mammal, the Hawaiian monk seal. Proceedings of the Royal Society of London B 274:407-415.

Beauplet G, Barbraud C, Chambellant M, Guinet G. 2005. Interannual variation in the post-weaning and juvenile survival of subantarctic fur seals: influence of pup sex, growth rate and oceanographic conditions. Journal of Animal Ecology 74: $1160-1172$.

Benton TG, Grant A, Clutton-Brock TH. 1995. Does environmental stochasticity matter? Analysis of red deer life-histories on Rhum. Evolutionary Ecology 9: $559-574$.

Bester MN. 1988. Marking and monitoring studies of the Kerguélen stock of southern elephant seals Mirounga leonina and their bearing on biological research in the Vestfold Hills. Hydrobiologia 165:269-277.

Bester MN. 1989. Movements of southern elephant seals and subantarctic fur seals in relation to Marion Island. Marine Mammal Science 5: 257-265. 
Bester MN, Wilkinson IS. 1994. Population ecology of southern elephant seals at Marion Island. In: Le Boeuf RJ, Laws RM (eds), Elephant seals: population ecology, behavior, and physiology, Berkeley: University of California Press. pp 85-97.

Biuw M, Boehme L, Guinet C, Hindell M, Costa D, Charrassin J-B, Roquet F, Bailleul F, Meredith M, Thorpe S, Tremblay Y, McDonald M, Park Y-H, Rintoul SR, Bindoff N, Goebel M, Crocker D, Lovell P, Nicholson J, Monks F, Fedak MA. 2007. Variations in behavior and condition of a Southern Ocean top predator in relation to in situ oceanographic conditions. PNAS 104: 13705-13710.

Boveng PL, Hiruki LM, Schwartz MK, Bengston JL. 1998. Population growth of Antarctic fur seals: limitation by a top predator, the leopard seal? Ecology 79: $2863-2877$.

Bowen WD, Iverson SJ, McMillan JI, Boness DJ. 2006. Reproductive performance in grey seals: age-related improvement and senescence in a capital breeder. Journal of Animal Ecology 75: 1340-1351.

Boyd IL. 2000. State-dependent fertility in pinnipeds: contrasting capital and income breeders. Functional Ecology 14: 623-630.

Bradshaw CJA, Hindell MA, Sumner MD, Michael KJ. 2004. Loyalty pays: life-history consequences of fidelity to marine foraging regions by elephant seals. Animal Behaviour 68: 1349-1360.

Bradshaw CJA, McMahon CR. 2008. Fecundity. In: Jørgensen SE, Fath BD (eds), Population Dynamics. Vol. 2 of Encyclopedia of Ecology. Oxford: Elsevier. pp $1535-1543$. 
Bradshaw CJA, McMahon CR, Hindell MA, Pistorius PA, Bester MN. 2002. Do southern elephant seals show density dependence in fecundity? Polar Biology 25: $650-655$.

Brook BW, Bradshaw CJA. 2006. Strength of evidence for density dependence in abundance time series of 1198 species. Ecology 87:1445-1451.

Burnham KP, Anderson DR. 2002. Model selection and multimodal inference: $a$ practical information-theoretic approach (2nd edn). New York: Springer.

Burnham KP, Anderson DR, White GC, Brownie C, Pollock KH. 1987. Design and analysis methods for fish survival experiments based on release-recapture. American Fisheries Society Monograph 5: 1-437.

Burton H. 1986. A substantial decline in numbers of the southern elephant seal at Heard Island. Tasmanian Naturalist 86: 4-8.

Campagna C, Fedak MA, McConnell BJ. 1999. Post-breeding distribution and diving behavior of adult male southern elephant seals from Patagonia. Journal of Mammalogy 80: 1341-1352.

Carlini AR, Daneri GA, Marquez MEI, Soave GE, Poljak S. 1997. Mass transfer from mothers to pups and mass recovery by mothers during the post-breeding foraging period in southern elephant seals (Mirounga leonina) at King George Island. Polar Biology 18: 305-310.

Caswell H. 2001. Matrix population models: construction analysis and interpretation. Sunderland: Sinauer Associates.

Caughley G. 1966. Mortality patterns in mammals. Ecology 47: 906-918.

Caughley G. 1977. Analysis of vertebrate populations. London: Wiley \& Sons.

Charrassin J-B, Hindell MA, Rintoul SR, Roquet F, Sokolov S, Biuw M, Costa D, Boehme L, Lovell P, Coleman R, Timmerman R, Meijers A, Meredith M, Park 
Y-H, Bailleul F, Goebel M, Tremblay Y, Bost C-A, McMahon CR, Field IC, Fedak M, Guinet C. 2008. Southern Ocean frontal structure and sea ice formation rates revealed by elephant seals. Proceedings of the National Academy of Science USA 105: 11634-11639.

Chilvers BL, Robertson BC, Wilkinson IS, Duignan PJ, Gemmell NJ. 2005. Male harassment of female New Zealand sea lions, Phocarctos hookeri: mortality, injury, and harassment avoidance. Canadian Journal of Zoology 83: 642-648.

Chown SL, Froneman PW (eds.). 2008. The Prince Edward Islands: Land-Sea Interactions in a Changing Ecosystem. S Stellenbosch: UN PReSS.

Condy PR. 1978. The distribution and abundance of southern elephant seals Mirounga leonina (Linn.) on the Prince Edward Islands. South African Journal of Antarctic Research 8: 42-48.

Condy PR. 1979. Annual cycle of the southern elephant seal Mirounga leonina (Linn.) at Marion Island. South African Journal of Zoology 14: 95-102.

Coulson T, Gaillard JM, Festa-Bianchet M. 2005. Decomposing the variation in population growth into contributions from multiple demographic rates. Journal of Animal Ecology 74: 789-801.

Daneri GA, Carlini AR. 2002. Fish prey of the southern elephant seals, Mirounga leonina, at King George Island. Polar Biology 25: 739-743.

Daneri GA, Carlini AR, Rodhouse PGK. 2000. Cephalopod diet of the southern elephant seal, Mirounga leonina, at King George Island, South Shetland Islands. Antarctic Science 12: 16-19.

de Bruyn PJN. 2009. Life history studies of the southern elephant seal population at Marion Island. $\mathrm{PhD}$ thesis, University of Pretoria, South Africa. 
de Bruyn PJN, Bester MN. 2010. Marion Island Marine Mammal Programme: Annual work plan M67. Unpublished report, Mammal Research Institute, University of Pretoria, South Africa.

de Bruyn PJN, Bester MN, Carlini AR, Oosthuizen WC. 2009. How to weigh an elephant seal with one finger: a simple three-dimensional photogrammetric field application. Aquatic Biology 5: 31-39.

de Bruyn PJN, Tosh CA, Bester MN, Cameron EZ, McIntyre T, Wilkinson IS (in press) Sex at sea: alternative mating system in an extremely polygynous mammal. Animal Behaviour.

de Bruyn PJN, Tosh CA, Oosthuizen WC, Phalandwa MV, Bester MN. 2008. Temporary marking of unweaned southern elephant seal (Mirounga leonina L.) pups. South African Journal of Wildlife Research 38: 133-137.

de Little SC, Bradshaw CJA, McMahon CR, Hindell MA. 2007. Complex interplay between intrinsic and extrinsic drivers of long-term survival trends in southern elephant seals. BMC Ecology 7:3.

Eberhardt LL. 1981. Population dynamics of the Pribilof fur seal. In: Fowler CW, Smith TD (eds), Dynamics of large mammal populations). New York: John Wiley \& Sons. pp 197-220.

Eberhardt LL, Siniff DB. 1977. Population dynamics and marine mammal management policies. Journal of the Fisheries Research Board of Canada 34: 183-190.

Festa-Bianchet M, Gaillard J-M, Cote SD. 2003. Variable age structure and apparent density dependence in survival of adult ungulates. Journal of Animal Ecology 72: 640-649.

Fowler CW. 1987. A review of density dependence in populations of large mammals. Current Mammalogy 1: 401-441. 
Frederiksen M, Daunt F, Harris MP, Wanless S. 2008. The demographic impact of extreme events: stochastic weather drives survival and population dynamics in a long-lived seabird. Journal of Animal Ecology 77: 1020-1029.

Fryxell JM. 1987. Food limitation and demography of a migratory antelope, the whiteeared kob. Oecologia 72: 83-91.

Gaillard JM, Allaine D, Pontier D, Yoccoz NG, Promislow DEL. 1994. Senescence in natural populations of mammals: a reanalysis. Evolution 48: 509-516.

Gaillard JM, Delorme D, Boutin J, Van Laere G, Boisaubert B, Pradel R. 1993. Roe deer survival patterns: a comparative analysis of contrasting populations. Journal of Animal Ecology 62: 778-791.

Gaillard JM, Festa-Bianchet M, Yoccoz NG. 1998. Population dynamics of large herbivores: variable recruitment with constant adult survival. Trends in Ecology and Evolution 13: 58-63.

Gaillard J, Sempere AJ, Boutin J, Van Laere G, Boisaubert B. 1992. Effects of age and body weight on the proportion of females breeding in a population of roe deer (Capreolus capreolus). Canadian Journal of Zoology 70: 1541-1545.

Gaillard J-M, Viallefont A, Loison A, Festa-Bianchet M. 2004. Assessing senescence patterns in populations of large mammals. Animal Biodiversity and Conservation 27: 47-58.

Galimberti F, Boitani L. 1999. Demography and breeding biology of a small, localized population of southern elephant seals (Mirounga leonina). Marine Mammal Science 15: 159-178.

Guinet C, Jouventin P, Weimerskirch H. 1992. Population changes and movements of southern elephant seals on Crozet and Kerguelen archipelagos in the last decades. Polar Biology 12: 349-356. 
Guinet C, Jouventin P, Weimerskirch H. 1999. Recent population change of the southern elephant seal at Îles Crozet and Îles Kerguelen: the end of the decrease? Antarctic Science 11: 193-197.

Hadley GL, Rotella JJ, Garrott, RA. 2007. Evaluation of reproductive costs for Weddell seals in Erebus Bay, Antarctica. Journal of Animal Ecology 76: 448-458.

Harting AL, Baker JD, Johanos TC. 2007. Reproductive patterns of the Hawaiian monk seal. Marine Mammal Science 23: 553-573.

Hastings KK, Testa JW, Rexstad EA. 1999. Interannual variation in survival of juvenile Weddell seals (Leptonychotes weddellii) from McMurdo Sound, Antarctica: effects of cohort, sex and age. Journal of Zoology, London 248: 307-323.

Hindell MA. 1991. Some life-history parameters of a declining population of southern elephant seals, Mirounga leonina. Journal of Animal Ecology 60: 119-134.

Hindell MA, Bradshaw CJA, Sumner MD, Michael KJ, Burton HR. 2003. Dispersal of female southern elephant seals and their prey consumption during the austral summer: relevance to management and oceanographic zones. Journal of Applied Ecology 40: 703-715.

Hindell MA, Burton HR. 1987. Past and present status of the southern elephant seal (Mirounga leonina) at Macquarie Island. Journal of Zoology, London 213: 365380.

Hindell MA, Little GJ. 1988. Longevity, fertility and philopatry of two female southern elephant seals (Mirounga leonina) at Macquarie Island. Marine Mammal Science 4: 168-171.

Hindell MA, Slip DJ, Burton HR. 1994. Possible causes of the decline of southern elephant seal populations in the Southern Pacific and Southern Indian Oceans. 
In: Le Boeuf RJ, Laws RM (eds), Elephant seals: population ecology, behavior, and physiology, Berkeley: University of California Press. pp 67-83.

Hofmeyr GJG. 2000. Dispersal and dispersion of southern elephant seals at Marion Island. M.Sc. thesis, University of Pretoria, South Africa.

Holmes EE, Fritz LW, York AE, Sweeney K. 2007. Age-structured modeling reveals long-term declines in the natality of western Steller sea lions. Ecological Applications 17: 2214-2232.

Hone J, Clutton-Brock TH. 2007. Climate, food, density and wildlife population growth rate. Journal of Animal Ecology 76: 361-367.

Huber HR, Rovetta AC, Fry LA, Johnston S. 1991. Age-specific natality of northern elephant seals at the South Farallon islands, California. Journal of Mammalogy 72: $525-534$.

Jonker FC, Bester MN. 1997/8. Seasonal movements and foraging areas of adult southern female elephant seals, Mirounga leonina, from Marion Island. Antarctic Science 10: 21-30.

Jorgenson JT, Festa-Bianchet M, Gaillard JM, Wishart WD. 1997. Effects of age, sex, disease, and density on survival of bighorn sheep. Ecology 78: 1019-1032.

Jorgenson JT, Festa-Bianchet M, Lucherini M, Wishart WD. 1993. Effects of body size, population density, and maternal characteristics on age at first reproduction in bighorn ewes. Canadian Journal of Zoology 71: 2509-2517.

Kendall WL, Nichols JD. 2002. Estimating state-transition probabilities for unobservable states using capture-recapture/resighting data. Ecology 83: 32763284 
Kirkman SP, Bester MN, Pistorius PA, Hofmeyr GJG, Jonker FC, Owen R, Strydom N. 2003. Variation in the timing of moult in southern elephant seals at Marion Island. South African Journal of Wildlife Research 33: 79-84.

Kirkman SP, Bester MN, Pistorius PA, Hofmeyr GJG, Owen R, Mecenero S. 2001. Participation in the winter haulout by southern elephant seals, Mirounga leonina. Antarctic Science 13: 380-384.

Lande R, Engen S, Saether B-E, Coulson T. 2006. Estimating density dependence from time series of population age structure. American Naturalist 168:76-87.

Laws RM. 1956. Growth and sexual maturity in aquatic mammals. Nature 178: 193194.

Lebreton J, Burnham KP, Clobert J, Anderson DR. 1992. Modelling survival and testing biological hypotheses using marked animals: a unified approach with case studies. Ecological Monographs 62: 67-118.

Lebreton J, Pradel R, Clobert J. 1993. The statistical analysis of survival in animal populations. Trends in Ecology and Evolution 8: 91-95.

Lima M, Paez E. 1997. Demography and population dynamics of South American fur seals. Journal of Mammalogy 78: 914-920.

Ling JK, Bryden MM. 1992. Mirounga leonina. Mammalian Species 391: 1-8.

Loison A, Festa-Bianchet M, Gaillard JM, Jorgenson JT, Jullien JM. 1999. Age-specific survival in five populations of ungulates: evidence of senescence. Ecology $80: 2539-54$

McIntyre T, Tosh CA, Bornemann H, Plötz J, Bester MN. 2010. Segregation in a sexually dimorphic mammal: a mixed-effects modelling analysis of diving behaviour in southern elephant seals. Marine Ecology Progress Series 412: 293304. 
McCann TS. 1985. Size, status and demography of southern elephant seal (Mirounga leonina) populations. In: Ling JK, Bryden MM (eds.). Sea Mammals of South Latitudes: Proceedings of a Symposium of the 52nd ANZAAS Congress in Sydney-May 1982. Northfield: South Australian Museum. pp 1-17.

McMahon CR, Bester MN, Burton HR, Hindell MA, Bradshaw CJA. 2005a. Population status, trends and a re-examination of the hypotheses explaining the recent decreases of the southern elephant seal, Mirounga leonina. Mammal Review $35: 82-100$.

McMahon CR, Bester MN, Hindell MA, Brook BW, Bradshaw CJA. 2009. Shifting trends: detecting environmentally mediated regulation in long-lived marine vertebrates using time-series data. Oecologia 159: 69-82.

McMahon CR, Bradshaw CJA. 2004. Harem choice and breeding experience of female southern elephant seals influence offspring survival. Behavioral Ecology and Sociobiology 55: 349-362.

McMahon CR, Burton HR. 2005. Climate change and seal survival: evidence for environmentally mediated changes in elephant seal, Mirounga leonina, pup survival. Proceedings of the Royal Society of London B 272: 923-928.

McMahon CR, Burton HR, Bester MN. 1999. First-year survival of southern elephant seals Mirounga leonina at sub-Antarctic Macquarie Island. Polar Biology 21: 279-284

McMahon CR, Burton HR, Bester MN. 2000. Weaning mass and the future survival of juvenile southern elephant seals, Mirounga leonina, at Macquarie Island. Antarctic Science 12: 149-153.

McMahon CR, Burton HR, Bester MN. 2003. A demographic comparison of two southern elephant seal populations. Journal of Animal Ecology 72: 61-74. 
McMahon CR, Field IC, Hindell MA, de Little SC, Bradshaw CJA. 2008. Guarding against oversimplifying the fundamental drivers of southern elephant seal population dynamics Journal of Biogeography 35: 1738-1740.

McMahon CR, Hindell MA, Burton HR, Bester MN. 2005b. Comparison of southern elephant seal populations, and observations of a population on a demographic knife-edge. Marine Ecology Progress Series 288: 273-283.

McMahon CR, White GC. 2009. Tag loss probabilities are not independent: Assessing and quantifying the assumption. Journal of Experimental Marine Biology and Ecology 372: 36-42.

Nevoux M, Weimerskirch H, Barbraud, C. 2007. Environmental variation and experience-related differences in the demography of the long-lived Blackbrowed Albatross. Journal of Animal Ecology 76: 159-167.

Nevoux M, Forcada J, Barbraud C, Croxall J, Weimerskirch H. 2010. Bet-hedging response to environmental variability, an intraspecific comparison. Ecology 91: $2416-2427$.

Nichols JD, Stokes SL, Hines JE, Conroy MJ. 1982. Additional comments on the assumptions of homogeneous survival rates in modern bird banding estimation models. Journal of Wildlife Management 46: 953-962.

Nussey DH, Coulson T, Festa-Bianchet M, Gaillard JM. 2008. Measuring senescence in wild animal populations: towards a longitudinal approach. Functional Ecology 22: 393-406.

Oftedal OT, Boness DJ, Tedman RA. 1987. The behavior, physiology, and anatomy of lactation in the pinnipedia. Current Mammalogy 1: 175-245. 
Oosthuizen WC, Bester MN, de Bruyn PJN, Hofmeyr GJG. 2009. Intra-archipelago moult dispersion of southern elephant seals at the Prince Edward Islands, southern Indian Ocean. African Journal of Marine Science 31: 457-462.

Oosthuizen WC, Bester MN, Tosh CA, Guinet C, Besson D, de Bruyn PJN (in press b). Dispersal and dispersion of southern elephant seals in the Kerguelen Province, Southern Ocean. Antarctic Science.

Oosthuizen WC, de Bruyn PJN, Bester MN (in press - a). Unmarked individuals in mark-recapture studies: comparisons of marked and unmarked southern elephant seals at Marion Island. Austral Ecology.

Oosthuizen WC, de Bruyn PJN, Bester MN, Girondot M. 2010. Cohort and tag-site specific tag-loss rates in mark-recapture studies: a southern elephant seal cautionary case. Marine Mammal Science 26: 350-369.

Pistorius PA. 2001. Life history parameters and regulation of the southern elephant seal population at Marion Island. PhD Thesis, University of Pretoria, South Africa.

Pistorius PA, Bester MN. 2002a. Juvenile survival and population regulation in southern elephant seals at Marion Island. African Zoology 37: 35-41.

Pistorius PA, Bester MN. 2002b. A longitudinal study of senescence in a pinniped. Canadian Journal of Zoology 80: 395-401.

Pistorius PA, Bester MN, Hofmeyr GJG, Kirkman SP, Taylor FE. 2008a. Seasonal survival and the relative cost of first reproduction in adult female southern elephant seals in relation to population changes in the Southern Indian Ocean. Journal of Mammalogy 89: 567-574.

Pistorius PA, Bester MN, Kirkman SP. 1999a. Survivorship of a declining population of southern elephant seals, Mirounga leonina, in relation to age, sex, and cohort. Oecologia 121: 201-211. 
Pistorius PA, Bester MN, Kirkman SP. 1999b. Dynamic age-distributions in a declining population of southern elephant seals. Antarctic Science 11: 445-450.

Pistorius PA, Bester MN, Kirkman SP, Boveng PL. 2000. Evaluation of age- and sexdependent rates of tag loss in southern elephant seals. Journal of Wildlife Management 64: 373-380.

Pistorius PA, Bester MN, Kirkman SP, Taylor FE. 2001a. Pup mortality in southern elephant seals at Marion Island. Polar Biology 24: 828-831.

Pistorius PA, Bester MN, Kirkman SP, Taylor FE. 2001b. Temporal changes in fecundity and age of maturity in the southern elephant seal population at Marion Island. Polar Biology 24: 343-348.

Pistorius PA, Kirkman SP, Bester MN, Taylor FE. 2002. Implications of the winter haulout for future survival and resighting probability of southern elephant seals at Marion Island. South African Journal of Wildlife Research 32: 59-63.

Pistorius PA, Bester MN, Lewis MN, Taylor FE, Campagna C, Kirkman SP. 2004. Adult female survival, population trend, and the implications of early primiparity in a capital breeder, the southern elephant seal (Mirounga leonina). Journal of Zoology, London 263: 107-119.

Pistorius PA, Bester MN, Taylor FE. 2005. Pubescent southern elephant seal males and the food limitation hypothesis. South African Journal of Wildlife Research 35: $215-218$.

Pistorius PA, Taylor FE, Bester MN, Hofmeyr GJG, Kirkman SP. 2008b. Evidence for density dependent population regulation in southern elephant seals in the southern Indian Ocean. African Zoology 43: 75-80. 
Pistorius PA, Taylor FE, Louw C, Hanise B, Bester MN, De Wet C, Du Plooy A, Green N, Klasen S, Podile S, Schoeman J. 2002c. Distribution, movement, and estimated population size of killer whales (Orcinus orca) at Marion Island, December 2000. South African Journal of Wildlife Research 32: 86-92.

Promislow DEL. 1992. Senescence in natural populations of mammals: a comparative study. Evolution 45: 1869-1887.

Promislow DEL, Harvey PH. 1990. Living fast and dying young: A comparative analysis of life-history variation among mammals. Journal of Zoology, London 220: 417-437.

Reid K, Croxall JP. 2001. Environmental response of upper trophic-level predators reveals a system change in Antarctic marine ecosystem. Proceedings of the Royal Society of (London) B. 268:366-384.

Reimers E. 1983. Reproduction in wild reindeer in Norway. Canadian Journal of Zoology 61: 211-217.

Reisinger RR, Bester MN. 2010. Long distance breeding dispersal of a southern elephant seal. Polar Biology 33:1289-1291.

Reisinger RR, de Bruyn PJN, Tosh CA, Oosthuizen WC, Mufanadzo NT, Bester MN (in press). Prey and seasonal abundance of killer whales at Subantarctic Marion Island. African Journal of Marine Science.

Rodhouse PG, Arnbom TR, Fedak MA, Yeatman J, Murray AWA. 1992. Cephalopod prey of the southern elephant seal, Mirounga leonina L. Canadian Journal of Zoology 70: 1007-1015.

Sæther B-E. 1997. Environmental stochasticity and population dynamics of large herbivores: a search for mechanisms. Trends in Ecology and Evolution 12: 143149. 
Saether BE, Engen S, Matthysen E. 2002. Demographic characteristics and population dynamical patterns of solitary birds. Science 295: 2070-2073.

Schaub M, Gimenez O, Schmidt BR, Pradel R. 2004. Estimating survival and temporary emigration in the multi-state capture-recapture framework. Ecology 85: 21072113.

Schwarz CJ, Stobo WT. 2000. Estimation of juvenile survival, adult survival, and agespecific pupping probabilities for the female grey seal (Halichoerus grypus) on Sable Island from capture-recapture data. Canadian Journal of Fisheries and Aquatic Science 57: 247-253.

Sibly RM, Barker D, Denham MC, Hone J, Page M. 2005. On the regulation of populations of mammals, birds, fish, and insects. Science 309: 607-610.

Slade RW. 1997. Genetic studies of the southern elephant seal, Mirounga leonina. In: Hindell MA, Kemper C (eds), Marine mammal research in the southern hemisphere (Vol. 1): Status, ecology and medicine. Chipping Norton: Surrey Beatty and Sons. pp 11-29.

Soto KH, Trites AW, Arias-Schreiber M. 2004. The effects of prey availability on pup mortality and the timing of birth of South American sea lions (Otaria flavescens) in Peru. Journal of Zoology 264: 419-428.

Stewart BS. 1992. Population recovery of Northern elephant seals on the Southern California Channel Islands. In: McCullough DR, Barret R (eds), Wildlife 2001: Populations. New York: Elsevier Applied Science Press.

Tavecchia G, Coulson T, Morgan BJT, Pemberton JM, Pilkington JC, Gulland FMD, Clutton-Brock TH. 2005. Predictors of reproductive cost in female Soay sheep. Journal of Animal Ecology 74: 201-213. 
Toigo C, Gaillard J, Michallet J. 1997. Adult survival pattern of the sexually dimorphic Alpine ibex (Capra ibex ibex). Canadian Journal of Zoology 75: 75-79.

Tosh CA. 2010. Oceanographic signatures and foraging areas of southern elephant seals. $\mathrm{PhD}$ thesis, University of Pretoria, South Africa.

Tosh CA, Bornemann H, Ramdohr S, Schröder M, Martin T, Carlini A, Plötz J, Bester MN. 2009. Adult male southern elephant seals from King George Island utilize the Weddell Sea. Antarctic Science 21: 113-121.

Trites AW, Larkin PA. 1989. The decline and fall of the Pribilof fur seal (Callorhinus ursinus): a simulation study. Canadian Journal of Fisheries and Aquatic Science 46: $1437-1445$.

van den Hoff J, Burton HR, Davies R. 2003. Diet of male southern elephant seals (Mirounga leonina L.) hauled out at Vincennes Bay, East Antarctica. Polar Biology 26: 27-31.

van den Hoff J, Burton HR, Hindell MA, Sumner MD, McMahon CR. 2002. Migrations and foraging of juvenile southern elephant seals from Macquarie Island within CCAMLR managed areas. Antarctic Science 14: 134-145.

Weimerskirch H, Inchausti P, Guinet C, Barbraud C. 2003. Trends in bird and seal populations as indicators of a system shift in the Southern Ocean. Antarctic Science 15: 249-256.

Weise MJ, Harvey JT, Costa DP. 2010. The role of body size in individual-based foraging strategies of a top marine predator. Ecology 91:1004-1015.

Wheatley KE, Bradshaw CJA, Davis LS, Harcourt RG, Hindell MA. 2006. Influence of maternal mass and condition on energy transfer in Weddell seals. Journal of Animal Ecology 75: 724-733. 
White GC, Burnham KP. 1999. Program MARK: survival estimation from populations of marked animals. Bird Study 46: 120-138.

Wilkinson IS. 1992. Factors affecting reproductive success of southern elephant seals, Mirounga leonina, at Marion Island. $\mathrm{PhD}$ thesis, University of Pretoria, South Africa.

Wilkinson IS, Bester MN. 1997. Tag-loss estimates for southern elephant seals, Mirounga leonina, at Marion Island. Antarctic Science 9: 162-167.

Wilkinson IS, Pascoe C, Bester MN. 1987. Marion Island Beach Descriptions. Unpublished report, Mammal Research Institute, University of Pretoria, South Africa.

Wilkinson I, van Aarde RJ. 1999. Marion Island elephant seals: the paucity-of-males hypothesis tested. Canadian Journal of Zoology 77: 1547-1554.

Wisdom MJ, Mills LS, Doak DF. 2000. Life stage simulation analysis: estimating vitalrate effects on population growth for conservation. Ecology 81: 628-641.

York AE. 1994. The population dynamics of northern sea lions, 1975-1985. Marine Mammal Science 10: 38- 51. 
Figure 1. The location of Marion Island in the Southern Indian Ocean.

Figure 2. Numbers of southern elephant seal pups born $(1986-2010)$ and tagged (1983 - 2010) at weaning age at Marion Island. Bars indicate the number of pups that survived to weaning age that escaped marking.

Figure 3. A probable model depicting population regulation in southern elephant seals at Marion Island. Level of importance of parameters (at each organizational level) in terms of governing population growth is indicated by the tone of the linking arrow $(\cdots=$ low; $-=$ medium; $-=$ high $) . *$ Note that this refers to proportion of three-year old females that have not commenced breeding. 


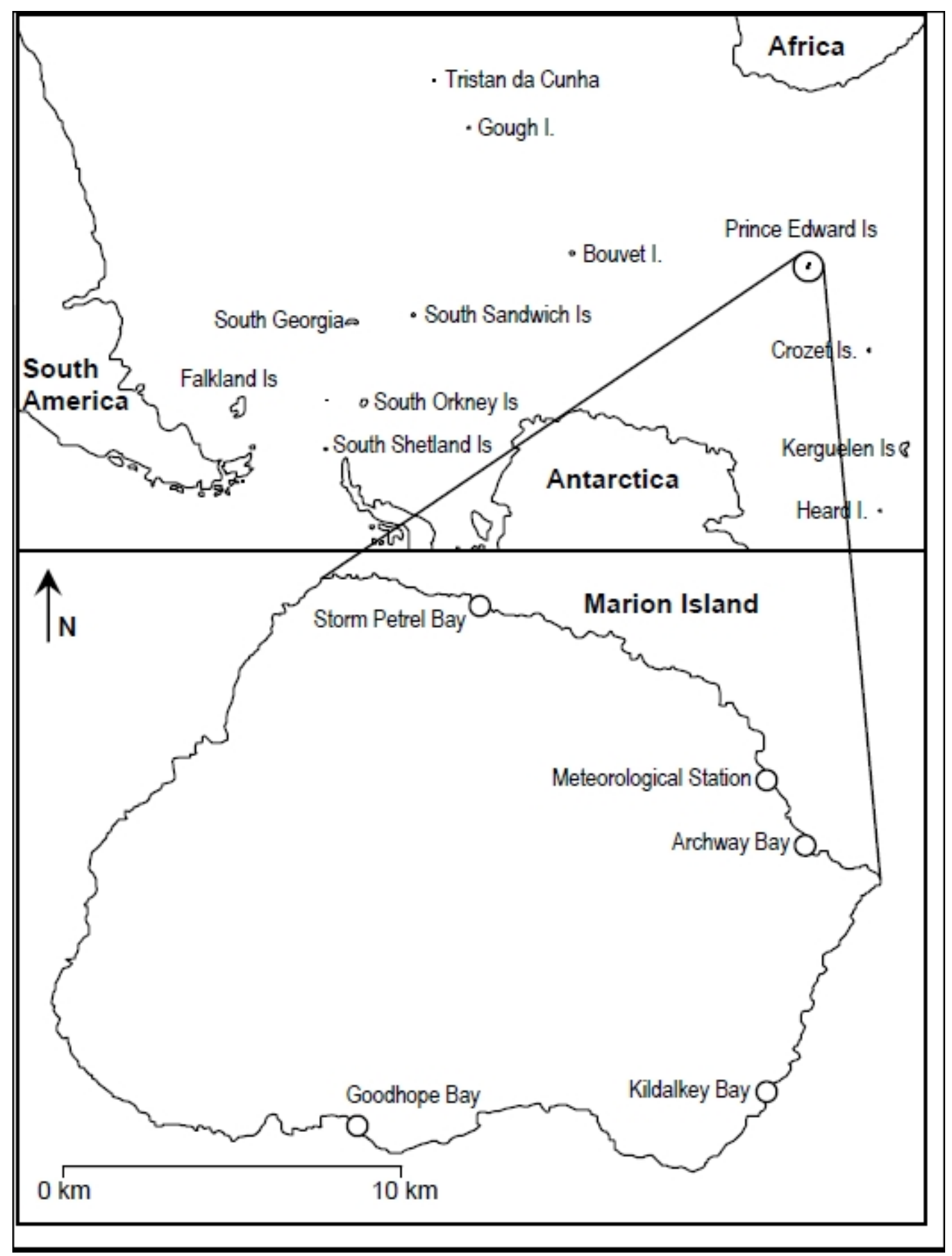




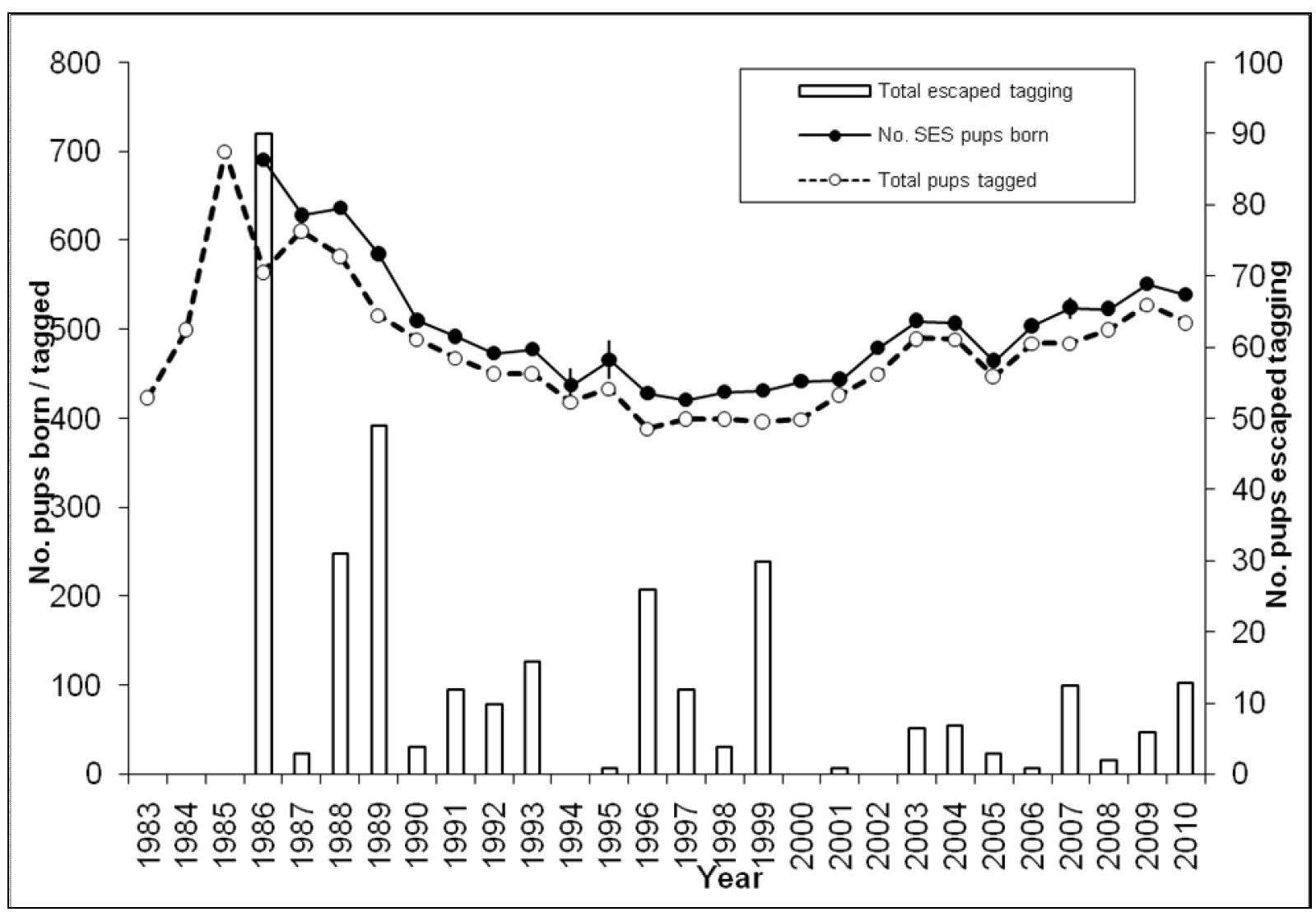




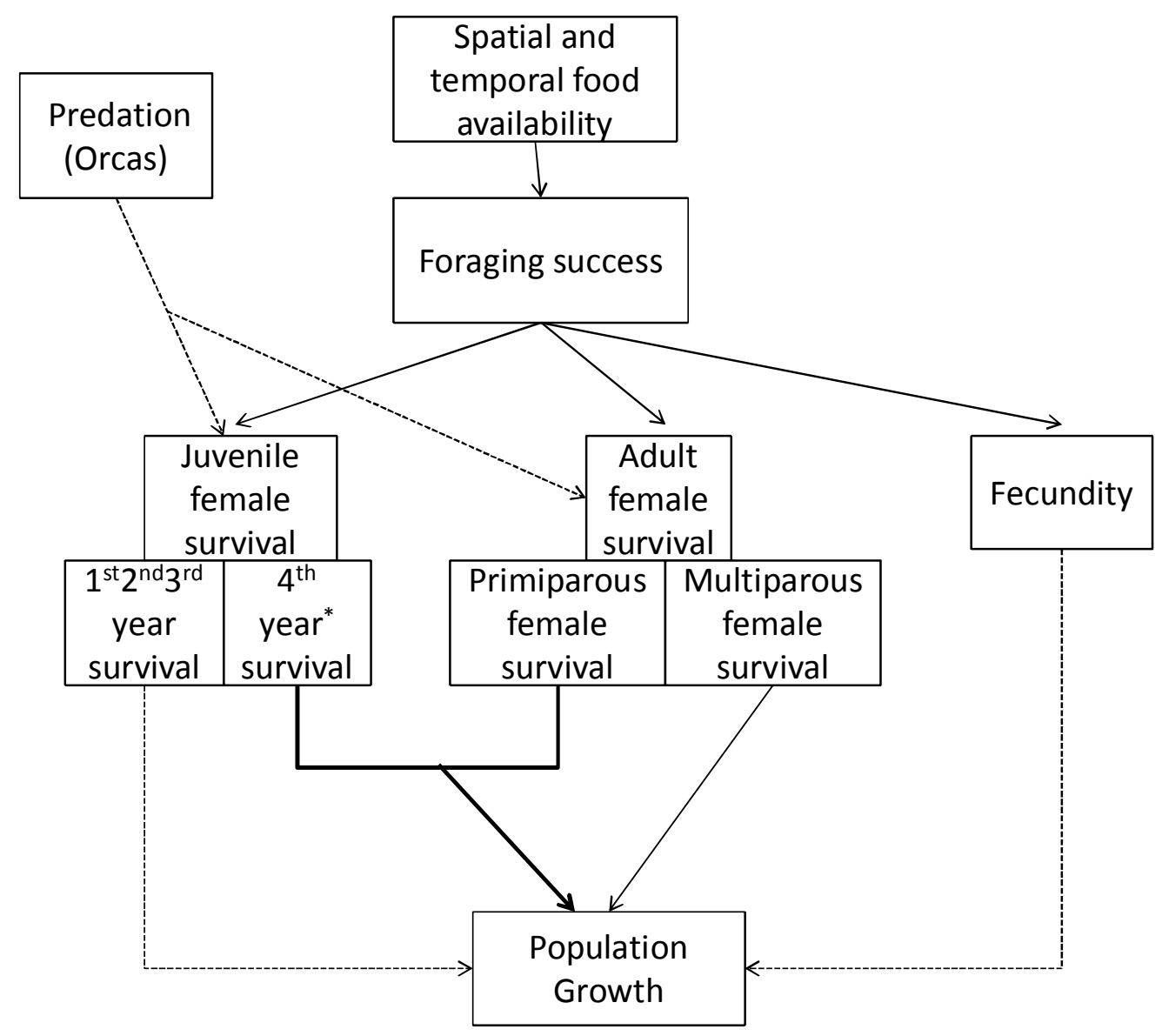

